\title{
Effect of predation by the invasive crab Hemigrapsus sanguineus on recruiting barnacles Semibalanus balanoides in western Long Island Sound, USA
}

\author{
Diane J. Brousseau ${ }^{1, *}$, Ronald Goldberg ${ }^{2}$ \\ ${ }^{1}$ Department of Biology, Fairfield University, Fairfield, Connecticut 06824, USA \\ ${ }^{2}$ National Oceanic and Atmospheric Administration, Northeast Fisheries Science Center, Milford Laboratory, \\ 212 Rogers Avenue, Milford, Connecticut 06460, USA
}

\begin{abstract}
Since its introduction fewer than $20 \mathrm{yr}$ ago, the spread of the Asian shore crab Hemigrapsus sanguineus along the east coast of the US has been remarkable. By many accounts it is now the numerically dominant brachyuran in rocky intertidal sites in Long Island Sound. Evidence from several laboratory studies has suggested that $H$. sanguineus could have significant consequences for barnacle abundance and distribution. In this study we used field caging experiments to determine the effect of this invader on recruitment (sampled at weekly intervals) of the indigenous barnacle Semibalanus balanoides. We found that although $H$. sanguineus readily consumed settling cypris larvae and early post-settlement juveniles, crab predation did not have a negative impact on barnacle recruitment when predator density was low $\left(15 \mathrm{crabs} 0.25 \mathrm{~m}^{-2}\right)$. We also found a measurable decrease in barnacle density at medium ( $\left.45 \mathrm{crabs} 0.25 \mathrm{~m}^{-2}\right)$ and high $\left(90 \mathrm{crabs} 0.25 \mathrm{~m}^{-2}\right)$ predator densities after the larval settlement period had ended, but this effect was short-lived. Based on available estimates of Asian shore crab abundance in Long Island Sound, we conclude that crab predation will not have a significant impact on the recruitment success of $S$. balanoides populations.
\end{abstract}

KEY WORDS: Hemigrapsus sanguineus - Asian shore crab · Predation impact - Caging study · Semibalanus balanoides $\cdot$ Barnacles $\cdot$ Recruitment $\cdot$ Long Island Sound

\section{INTRODUCTION}

As the numbers of documented occurrences of marine and estuarine invasions by nonindigenous species increase, there is growing concern among ecologists that these invasions pose a serious biological threat with potentially harmful consequences for the ecology of invaded environments (Cohen \& Carlton 1998). In some instances, dramatic changes in prey species abundance and alterations in community structure and function have resulted when exotic species have become numerically dominant in invaded communities (Nichols et al. 1990, Lambert et al. 1992, Travis 1993, Grosholz et al. 2000). For the majority of recent marine invasions, however, it is less clear what effect, if any, will be felt on the distribution and abundance of native species, because experimental field tests designed to demonstrate and quantify their effects are rare.

The Asian shore crab Hemigrapsus sanguineus is a recent and particularly successful introduction to the east coast of the United States. It was first observed in New Jersey in 1988 (Williams \& McDermott 1990) and now ranges from Maine to North Carolina. In less than 20 yr, it has become the most abundant crab species of many rocky intertidal habitats in Long Island Sound (Lohrer \& Whitlatch 2002, Ahl \& Moss 1999). The remarkable success of this invader is probably due to 
its large reproductive capacity and extended spawning season (Fukui 1988, McDermott 1998a), the wide dispersal of its planktonic larvae (Parks et al. 2004), high adult mobility (Brousseau et al. 2002), and adaptability to a broad range of environmental conditions (Gerard et al. 1999).

As an opportunistic omnivore, Hemigrapsus sanguineus consumes widely diverse prey including small invertebrates such as amphipods, bivalves, barnacles, gastropods, and polychaetes, as well as macroalgae and detritus (Lohrer \& Whitlatch 1997, Brousseau et al. 2000). It is particularly adept at scraping food from hard surfaces (McDermott 1998b), but it can crush or chip open small shelled prey. In the laboratory $H$. sanguineus has a demonstrable impact on juvenile shellfish prey (Brousseau \& Baglivo 2001, Lohrer \& Whitlatch 2002, Bourdeau \& O'Connor 2003) and the green crab Carcinus maenas (Jensen et al. 2002). Microcosm experiments run under laboratory and natural conditions also show that predation by $H$. sanguineus causes significant declines in juvenile mussels, barnacles, and ephemeral algae (Tyrrell et al. 2006). While some investigators have suggested that Asian shore crab impact will be minimal, others have predicted negative effects from crab predation and grazing. It remains unclear, however, if the observed competitive and predatory behavior of $H$. sanguineus has an impact on the abundance and distribution of these species in nature.

Caging experiments have been widely used in marine ecology to measure the importance of predation on rocky shores (Paine 1966, Connell 1970, Lubchenko \& Menge 1978), in benthic soft-sediment environments (Thrush 1986, Fishman \& Orth 1996, Armitage \& Fong 2006, Moksnes \& Heck 2006), on fouling assemblages (Brown \& Swearingen 1998), and by nonindigenous species (Grosholz et al. 2000, Walton et al. 2002 Lohrer \& Whitlatch, 2002). Since barnacles are important space competitors and dominant organisms in structuring the intertidal zone, it is important to understand the role of nonindigenous species such as Hemigrapsus sanguineus in controlling barnacle population dynamics.

Recruitment is defined here as the combined result of larval settlement and early post-settlement mortality (for discussion see Minchinton \& Scheibling 1993), both of which are influenced by physical and biological factors. Our study was conducted during the spring recruitment period of Semibalanus balanoides using settling plates to capture naturally-occurring cypris larvae. Since annual barnacle recruitment in this region is both consistent and predictable (Lang \& Ackenhusen-Johns 1981, and authors' pers. obs.) there was no need to artificially manipulate prey density (as is often required in studies of this sort). Consequently, our experimental design allowed us to assess effects of crab predation in a dynamic system controlled solely by natural recruitment processes. In this study, we designed and conducted field caging experiments to assess the impact of Hemigrapsus sanguineus predation on recruitment of the barnacle $S$. balanoides in western Long Island Sound.

\section{MATERIALS AND METHODS}

Caging experiments. From 2003 to 2005 we conducted a series of caging experiments to determine the effects of the invasive crab Hemigrapsus sanguineus on recruitment (settlement and early post-settlement survival) of the native barnacle Semibalanus balanoides. All experiments were conducted in the mid-intertidal zone at the mouth of Black Rock Harbor, Bridgeport, Connecticut $\left(41^{\circ} 08.8^{\prime} \mathrm{N}\right.$ latitude, $73^{\circ} 13.5^{\prime} \mathrm{W}$ longitude). This site is characterized by a gently sloping tidalflat densely covered with rocks of various sizes. A seawall constructed of large boulders forms the shoreward boundary of the study area. Natural crab densities at the site were determined along 2 vertical transects within the intertidal zone by counting all Asian shore crabs present within a metal frame $\left(0.25 \mathrm{~m}^{2}\right)$ placed on the substrate at each haphazardly-determined sampling point $(\mathrm{N}=15)$.

Caging experiments were conducted in each of the 3 yr from April to mid-June. We used different cage treatments to test the null hypothesis that Asian shore crab predation has no effect on annual barnacle recruitment. In 2003 and 2004 enclosure treatments (crabs added; $15 \mathrm{cage}^{-1}$ ) were used to measure predation effects of the shore crabs on barnacles. Exclosure cages (with crabs removed) measured background mortality in the absence of shore crab predators too large to enter the cages $(\sim 12 \mathrm{~mm})$. Open plots (no cages) were used to measure natural mortality and partial cages tested for possible cage artifacts. These treatments also allowed us to account for any potential cage effects on barnacle larval settlement from the plankton. In 2005 we tested for the effects of predator density on barnacle recruitment. Treatments included exclosure cages (crabs removed) and enclosure cages at low crab density $\left(15\right.$ cage $\left.^{-1}\right)$, medium crab density $\left(45\right.$ cage $\left.^{-1}\right)$, and high crab density $\left(90\right.$ cage $\left.^{-1}\right)$.

Four replicates of each treatment were used in all experiments. Vinyl-coated wire mesh $(10 \mathrm{~mm})$ openbottomed cages with a single, hinged access door on top were used. The cages were buried in the sediment to an approximate depth of $10 \mathrm{~cm}$ resulting in an enclosed area of $0.6 \times 0.4 \times 0.2 \mathrm{~m}$ high. All cage and open plot treatments were placed approximately $1 \mathrm{~m}$ apart using a Latin square pattern. 
Prior to the start of each experiment, Plexiglas ${ }^{\mathrm{TM}} \mathbf{1}$ settling plates $(35.5 \times 22.5 \mathrm{~cm})$, each with 8 rectangles $(7.5 \times 5.0 \mathrm{~cm})$ of $3-\mathrm{M}^{\mathrm{TM}}$ non-skid tape were placed in each cage and open plot. Previous studies in the laboratory had shown non-skid tape to be an effective 'settling surface' for Semibalanus balanoides larvae and it provided a uniform surface area for comparisons. Once barnacle settlement had occurred (usually within 1 wk of field placement), tagged crabs were added to the enclosure cages. Experimental crabs were collected by hand haphazardly from the field site and were representative of the general size distribution and sex ratio of the natural population. Crabs smaller than $12 \mathrm{~mm}$ were excluded since these crabs could pass through the mesh openings of the cages. Crabs were returned to the Milford Laboratory for tagging and each crab was marked by gluing with cyanoacrylate a small color/shape-coded plastic tag to the carapace. Recovery rates were estimated by counting the number of tagged crabs present in the enclosure cages at the end of each experiment. For all tagged crabs, maximum carapace width (CW) was measured to the nearest $0.1 \mathrm{~mm}$ with Vernier calipers and sex was determined. Mean CW of crabs collected from the natural population and used in the experiments was $17.8 \pm 0.3 \mathrm{SE}$ in $2003,22.9 \pm 1.7 \mathrm{SE}$ in 2004 , and $17.9 \pm$ $0.2 \mathrm{SE}$ in 2005. Overall the CW of crabs collected in all years ranged from 13.7 to $38.5 \mathrm{~mm}$. The sex ratio of crabs in 2003 was approximately $2: 1$; in 2004, 4.5:1; and in 2005, 2.2:1. Only crabs whose chelae and other appendages were intact were used. Crabs were held overnight in running seawater and placed in cages the following day. Prior to release, caged plots were cleared of all visible Hemigrapsus sanguineus.

Once a week, all settling plates were photographed in the field using a digital camera. Numbers of live barnacles attached to the 8 'settling surfaces' on each plate were determined by counting from printed digital images. These weekly counts were cumulative in that they included both newly settled cyprids and those which had successfully settled and recruited to the plates during the experimental period. The mean maximum basal diameter of Semibalanus balanoides at the end of each experiment was $2.48 \pm 0.11 \mathrm{~mm}$. Because of noticeable fouling of the settling plates by green macroalgae (primarily Ulva sp.) at the termination of the experiment in 2005, we returned the plates to the laboratory to determine relative amounts of algae in each experimental treatment. We used a transparent dot grid $(\mathrm{N}=192)$ superimposed on the settling surface to estimate percentage algal cover. Upon conclusion of each experiment, all tagged and

1 Use of trade names does not imply the endorsement of the National Oceanic and Atmospheric Administration untagged Hemigrapsus sanguineus were removed from the cages and counted.

Diet analysis. During the experimental period, wild crabs (8.8 to $38.3 \mathrm{~mm} \mathrm{CW}$ ) were collected weekly during low tide from the area immediately adjacent to the experimental site. On collection day, stomachs were removed from live crabs and their contents flushed with seawater into a Petri dish and examined under a dissecting microscope to determine food type. Cypris larvae were counted and the presence of barnacle shell fragments was noted. Sample sizes ranged from 20 to 50 crabs. In 2005, stomachs of experimental crabs $(\mathrm{N}=34)$ retrieved from cages at the end of caging experiments were also analyzed for content.

Statistical analysis. Counts of barnacles from the 8 settling surfaces on each plate were averaged to produce 1 value for each of the 4 replicate experimental units of each treatment. Data were tested for normality and homogeneity of variance. When these assumptions were met, 1-way ANOVA $(\alpha=0.05)$ was used to compare barnacle density and percentage cover of macroalgae on the settling plates in the different treatments. Post-hoc comparisons were made using Student-Newman-Keuls tests. In the few cases when data did not meet the assumptions of ANOVA, a non-parametric Kruskal-Wallis analysis of variance on ranks was used for comparison. All analyses were performed using SigmaStat 3.1 software (Systat Software).

\section{RESULTS}

\section{Caging experiments}

In 2003, the beginning of the experiment coincided with the active larval settlement period of Semibalanus balanoides. Initial Hemigrapsus sanguineus densities of 15 crabs $0.25 \mathrm{~m}^{-2}$ within enclosure cages approximated natural Asian shore crab density on the tidalflat within the immediate study area $(10 \pm 1.3$ crabs $0.25 \mathrm{~m}^{-2}$ ). Mean recovery rate of tagged crabs within enclosures at the end of the experiment was $85 \%$. Statistical comparison of all treatments combined (enclosure, exclosure, partial, open) showed a statistically significant difference in barnacle density on the initial sampling date only (Fig. 1a). This was due to significantly higher barnacle density in open plots than in the cage treatments $(F=4.78$, df $=3,12, p=0.02)$, suggesting cage interference with larval settlement onto the plates. This apparent cage effect disappeared after the first week and there was no measurable difference in barnacle density among treatments ( $>$ > 0.05) throughout the remainder of the active settlement and early post-settlement period. 

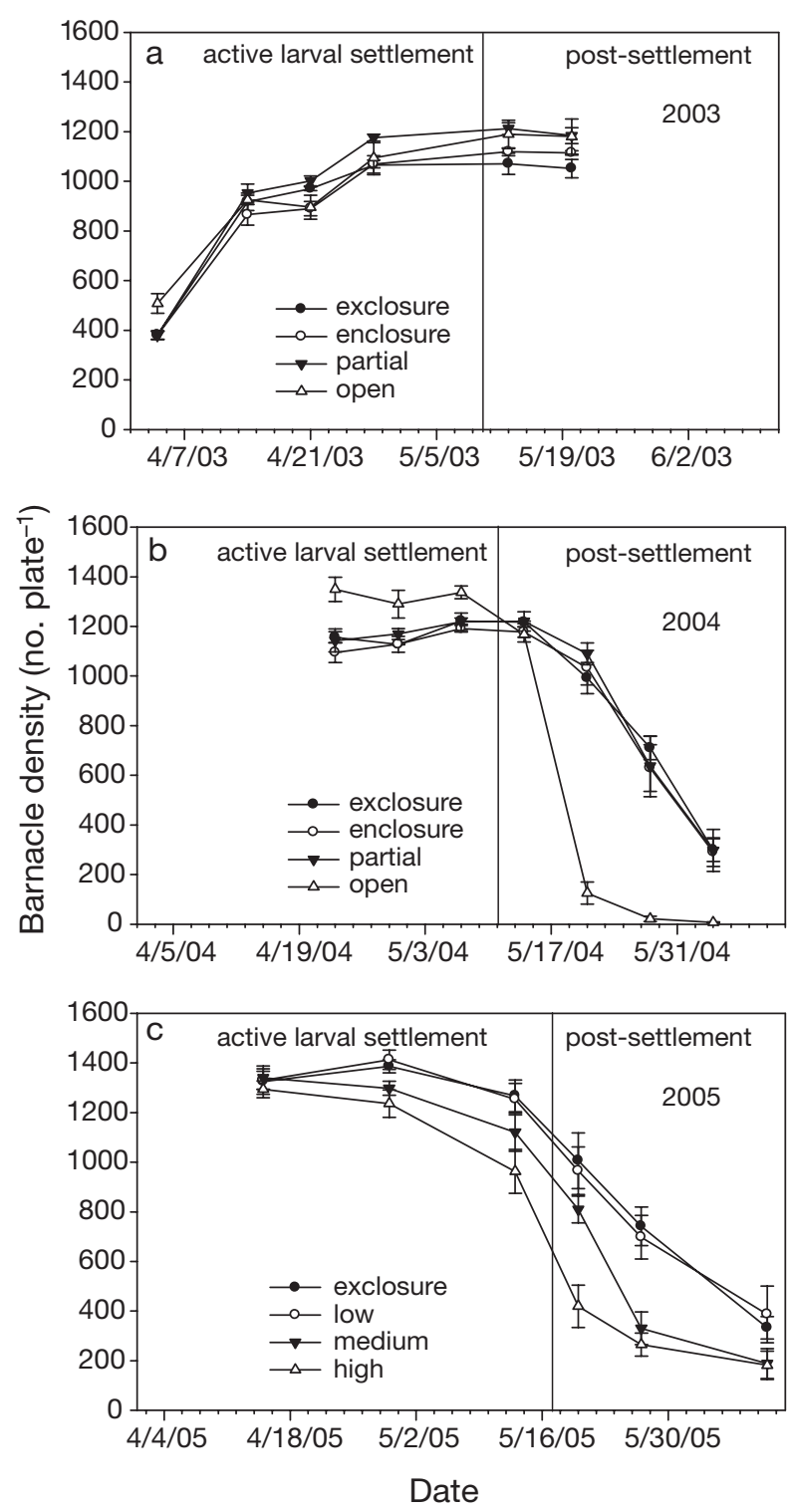

Fig. 1. Hemigrapsus sanguineus and Semibalanus balanoides. Mean $( \pm$ SE) barnacle density in 4 experimental treatments (predator exclosure, predator enclosure [15 crabs $0.25 \mathrm{~m}^{-2}$ ], partial cages, and open cages) on each sampling date in (a) 2003, (b) 2004, and (c) predator exclosure and enclosure (low, medium, and high $=15,45$, and 90 crabs $25 \mathrm{~m}^{-2}$, respectively) in 2005. Vertical line marks observed transition from active larval settlement to post-settlement phase during the barnacle recruitment period. Dates $=\mathrm{mo} / \mathrm{d} / \mathrm{yr}$

In 2004, the experiment began later in April than the previous year, but extended an additional 2 wk into the barnacle post-settlement period. Initial crab densities were the same as in 2003, but the mean recovery rate of tagged crabs was slightly lower $(75 \%)$. As in 2003 , open plots had significantly more larval recruits than caged treatments during the settlement period $(\mathrm{p}<$ 0.05). On all post-settlement sampling dates, except the first (May 15), there were statistically significantly lower barnacle densities in the open treatments compared to the cage treatments (Fig. 1b). The lower barnacle post-settlement survival in open treatments may have been due to added predation pressure from other species, to lack of cage shading resulting in higher desiccation mortality, or both. When open treatments were removed from the analysis, no statistically significant differences in barnacle density were found among the cage treatments $(p>0.05)$.

In the 2005 experiment to test the effect of predator density, there was no statistically significant difference in barnacle density among treatments (exclosure, low, medium, high) during the larval settlement period on the first 2 sampling dates $(p>0.05)$, despite the 6-fold difference in initial crab densities (Fig. 1c). By the third sample date, May 13, differences in survival among the treatments began to emerge $(F=2.67, \mathrm{df}=3,12$, $\mathrm{p}=0.043)$. Post-hoc tests indicated statistically significantly lower barnacle densities in the May 20 and May 30 samples $(p<0.05)$ in the enclosures with high and medium crab densities after settlement ceased. At the end of the experiment, barnacle density was reduced by $70 \%$ in all treatments with no statistically significant differences $(p>0.05)$. Exclosure and low density predator treatments were not statistically significantly different throughout the entire experiment $(p>0.05)$. Mean crab recovery rate in all enclosures combined was $70 \%$, but recovery rates among enclosure treatments varied. Percentage recovery increased in each treatment in relation to stocking density (low density $=86.5 \pm 0.06 \mathrm{SE}$, medium density $=69.4 \pm$ $0.06 \mathrm{SE}$, high density $=55.8 \pm 0.09 \mathrm{SE}$ ).

Although not statistically significant $(F=2.18, \mathrm{df}=3$, $12, p=0.143)$, there was a strong trend of decreasing percentage cover of algae (Ulva sp.) on settling plates in relation to higher crab densities in the experimental treatments, probably caused by increased grazing activity. At the end of the experiment, percentage algal cover was $71.8 \pm 22.6 \mathrm{SE}$ in the exclosure treatment, $67.7 \pm 18.7 \mathrm{SE}$ in the low crab density treatment, $35.1 \pm$ 12.3 $\mathrm{SE}$ in the medium crab density treatment, and $22.9 \pm 7.3 \mathrm{SE}$ in the high crab density treatment.

\section{Diet analysis}

Of the Hemigrapsus sanguineus examined, 86\% (681 of 796) had consumed food before capture; the rest had empty stomachs when dissected. Food items found in crab diets varied in type and amount. In addition to barnacles Semibalanus balanoides, detritus, macroalgae, and juvenile polychaete worms were present in some crab stomachs. Cypris larvae appeared in $43.5 \%$ of crab stomachs sampled during April when 
data from all years were combined. They were absent from those sampled after the first week in May 2003 and the second week in May 2004 and 2005, signaling the end of settlement. Crushed barnacles (shells) were present in crab stomachs on every date sampled and were found in at least $45 \%$ of crabs from mid-April to mid-June. By the end of May, the numbers of crabs feeding on green algae increased dramatically, especially in 2003 and 2004. Experimental crab stomachs analyzed in 2005 contained similar proportions of the same food items as those of wild crabs collected on the same date (Fig. 2). Numbers of cypris larvae present in
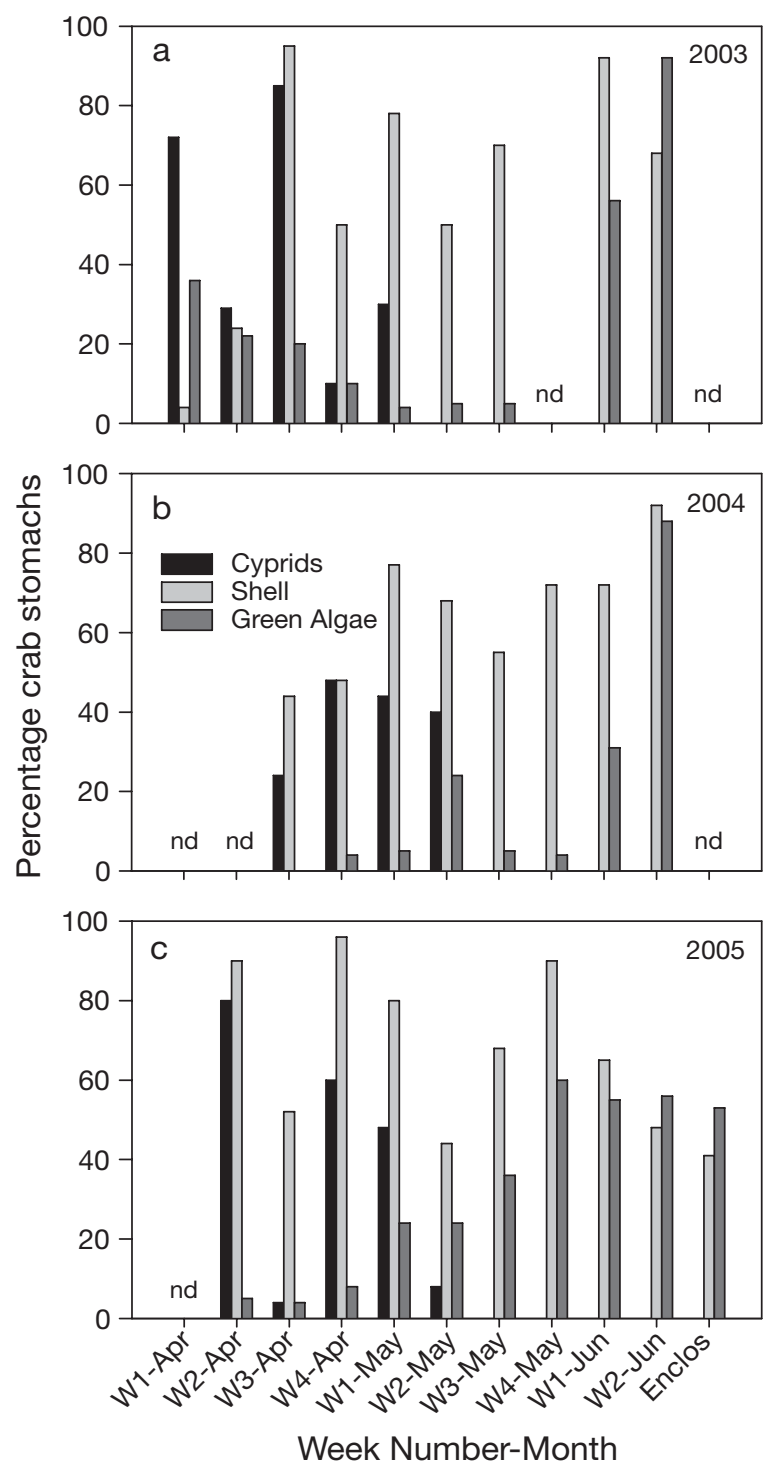

Fig. 2. Hemigrapsus sanguineus and Semibalanus balanoides. Percentage of crab stomachs analyzed weekly in (a) 2003, (b) 2004 and (c) 2005 containing 1 or more of the food items barnacle cyprids, barnacle shells, and green algae. Enclos $=$ crabs from predator enclosure cages sampled on June 10, 2005; nd = no data

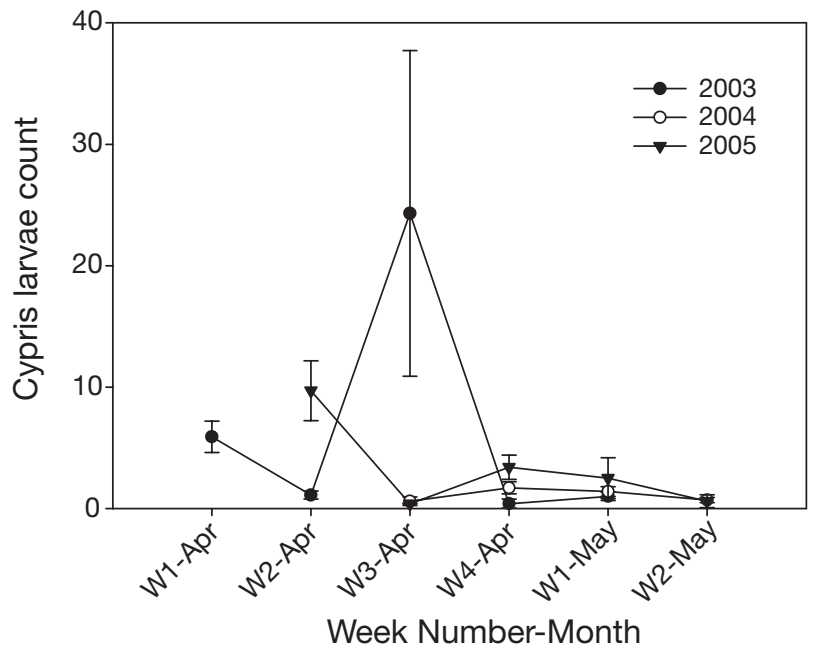

Fig. 3. Hemigrapsus sanguineus and Semibalanus balanoides. Mean $( \pm \mathrm{SE})$ number of barnacle cypris larvae found in stomachs of crabs analyzed weekly during the larval settlement phase in 2003 to 2005. (No data available for W1-Apr 04, W2-Apr 04, W2-Apr 05)

crab stomachs varied with sampling date, but averaged fewer than $10 \mathrm{crab}^{-1}$ for all dates, with 1 exception (W3-Apr 03), when 2 crabs were found with more than 100 larvae in their stomachs (Fig. 3).

\section{DISCUSSION}

The importance of biotic processes in determining the abundance and distribution of barnacles in rocky environments has been well documented (for reviews see Connell 1985, Rodriguez et al. 1993, Caley et al. 1996, Jeffrey 2003). Studies focusing on the role of predation in controlling barnacle recruitment success have shown that the impact of predation is dependent on predator type, barnacle species, and position on the shore relative to tidal height. Intertidal limpets and periwinkles affect barnacle recruits directly by 'bulldozing' them off the settling surface (Buschbaum 2000, Holmes et al. 2005) or inadvertently consuming them while grazing algae (Miller \& Carefoot 1989). Exclusion experiments have shown that recruitment of the barnacle Balanus crenatus to subtidal mussel beds is strongly affected by green crabs Carcinus maenas and seastars Asterias rubens, but impacts of these nonmolluscan predators on the intertidal barnacle, Semibalanus balanoides are minimal (Buschbaum 2002).

The Asian shore crab Hemigrapsus sanguineus resides primarily in the intertidal zone, where it seeks the shelter of rocks at low tide and emerges to feed when the tide is high. Laboratory observations confirm that the Asian shore crab readily removes recruited barnacles from substrate surfaces (rocks, settling plates) 
and consumes them (McDermott 1998b, D. J. Brousseau unpubl.). Because of its small size (generally $<50 \mathrm{~mm} \mathrm{CW}$ ), however, it is capable of eating only juvenile shelled prey (Brousseau \& Baglivo 2001), suggesting that the greatest predation impact in natural populations would occur early in the barnacle life cycle. In western Long Island Sound the recruitment period of Semibalanus balanoides overlaps with the onset of the seasonal activity cycle of $H$. sanguineus in mid- to late March. Our diet analyses indicate that the majority of dissected crabs had cyprids and/or barnacle shells in their stomachs, pointing to the importance of both larval and early postlarval barnacles as a food source for crabs at a time of the year when the diversity of other available food items (i.e. barnacles, algae, clamworms, detritus) is low.

Despite such evidence supporting the hypothesis that Hemigrapsus sanguineus predation is a potentially important process in determining barnacle recruitment success, our caging studies revealed little or no effect on barnacle recruitment at the crab densities tested. Barnacle density on the settling plates increased over time in almost all treatments during the settlement periods in each of the $3 \mathrm{yr}$. In addition, no statistically significant difference was found among predator enclosures and exclosure treatments, indicating that feeding activity by $H$. sanguineus has no measurable effect on cyprid recruitment. Although grazed areas were visible on the settling plates on each sampling date, there was photographic evidence that the empty space was subsequently utilized by new recruits. The effect of cyprid removal by crabs was offset by recolonization, suggesting that an abundant planktonic larval supply is an effective barnacle adaptation to minimize the effects of predation pressure on settling barnacle larvae.

A negative impact on barnacle survival was measured after larval settlement had ended, but the effect was temporary and highly dependent on predator density. During the last 2 wk in May 2005, post-settlement survival in moderate and high density enclosures was statistically significantly lower than that in exclosure cages. By early June, however, this predation effect had disappeared, resulting in no lasting impact on barnacle density. No effect on barnacle survival in low density cages was observed in either 2004 or 2005. After active larval settlement had ended, the gradual decline in barnacle survival in the low and predator exclusion cages approximated a rate of background mortality in nature resulting from biotic and abiotic factors.

The low to moderate density of Asian shore crabs at our experimental site $\left(40 \mathrm{crabs} \mathrm{m}^{-2}\right)$ is similar to that reported for other sites in Long Island Sound (New Haven: 2.6 to $5.6 \mathrm{crab} \mathrm{m}^{-2}$, Hammonasset: 17.9 crabs $\mathrm{m}^{-2}$, Lohrer \& Whitlatch 1997; Greenwich Point:
22.8 crabs m$^{-2}$, Ahl \& Moss 1999; Crane Neck Point: 7.1 to $10.3 \mathrm{crabs} \mathrm{m}^{-2}$, Gerard et al. 1999). Based on our experiments, we predict that little impact on barnacle population size and/or distribution would be expected at any of these sites. At 1 site in eastern Long Island Sound where reported maximum crab densities often exceed 150 crabs m$^{-2}$ (Millstone Point; Lohrer \& Whitlatch 2002), Asian shore crab predation could potentially cause modest decreases in barnacle abundance in intertidal communities.

Non-quantitative estimates of relative food abundance derived from stomach content analyses show that Asian shore crabs take advantage of the availability of barnacle food items (cyprids and post-metamorphic juveniles) during the spring months. Since crab predation pressure in spring may not be as intense as it is later in the year because of decreased metabolic activity resulting from lower water temperatures, the timing of barnacle recruitment may help reduce predation impacts. In June (Fig. 2) and throughout the summer, an increased number of crabs eat algal species, suggesting that the diet of Asian crabs broadens as additional food items become available and feeding pressure intensifies. By the end of July, the number of crabs with barnacles in their diet has decreased considerably ( $<20 \%$ in 2003 to 2005; D. J. Brousseau unpubl.). Studies in the laboratory have shown that increased crab density also leads to increased diet breadth in Hemigrapsus sanguineus (Brousseau \& Baglivo 2005). The trend of decreased algal cover on settling plates in cage enclosures at the end of our study supports the occurrence of a diet shift in the field. Crab dependence on barnacles would be expected to diminish as juvenile barnacles approach a size-refuge from predation.

It is well documented that populations of the invasive Asian shore crab Hemigrapsus sanguineus have exploded in rocky intertidal habitats in eastern Long Island Sound. Lohrer \& Whitlatch (2002) report average densities exceeding 70 crabs $\mathrm{m}^{-2}$ and a numerical dominance of $>90 \%$ over other crabs in several areas in this region. Because of these alarming statistics, many have hypothesized that this invader is likely to cause substantial ecological changes in the resident marine benthic community. In a manipulative field study comparing the relative impacts of 2 exotic species on native blue mussels Mytilus edulis, Lohrer \& Whitlatch (2002) found Carcinus maenas to have the higher prey consumption rates, but speculated that impact by $H$. sanguineus would be more important from a blue mussel population standpoint, because of this crab's extraordinary abundance in some intertidal locations. The results of our study do not support this conclusion for the impact of the invasive crab on barnacle recruitment, and emphasize the need for specific process-oriented studies. 
The Asian shore crab invasion is arguably the most significant by a brachyuran predator of the NE coast of North America since the introduction of the green crab Carcinus maenas almost $200 \mathrm{yr}$ ago. This invasion has been viewed by some as a potentially influential structuring force in rocky intertidal communities of this region. Our study has shown, however, that despite its numerical dominance and opportunistic feeding behavior, Hemigrapsus sanguineus has only transitory effects on barnacle recruitment. While future studies may show $H$. sanguineus to be a risk to other organisms of rocky intertidal environments, we conclude that at present population levels crab predation will not have a significant negative impact on recruitment success in Semibalanus balanoides populations in western Long Island Sound.

Acknowledgements. We thank J. Ajaj, J. Eyzaguirre and F. Rossi for providing assistance deploying the field cages and B. Hooper and A. M. Salvato for help in processing the digital images. We also thank the 3 anonymous reviewers who read an earlier version of this manuscript for their helpful suggestions. This work was supported in part by Fairfield University through a sabbatical leave to D. Brousseau.

\section{LITERATURE CITED}

Ahl RS, Moss SP (1999) Status of the nonindigenous crab, Hemigrapsus sanguineus at Greenwich Point, Connecticut. Northeast Nat 6:221-224

Armitage AR, Fong P (2006) Predation and physical disturbance by crabs reduce the relative impacts of nutrients in a tidal mudflat. Mar Ecol Prog Ser 313:205-213

Bourdeau PE, OConnor NJ (2003) Predation by the nonindigenous Asian shore crab Hemigrapsus sanguineus on macroalgae and molluscs. Northeast Nat 10:319-334

Brousseau DJ, Baglivo JA (2001) Laboratory investigations of the effects of predator sex and size on prey selection by the Asian crab, Hemigrapsus sanguineus. J Exp Mar Biol Ecol 262:191-210

Brousseau DJ, Baglivo JA (2005) Laboratory investigations of food selection by the Asian shore crab, Hemigrapsus sanguineus: algal versus animal preference. J Crustac Biol 25: 130-134

Brousseau DJ, Korchari PG, Pflug C (2000) Food preference studies of the Japanese shore crab (Hemigrapsus sanguineus) from western Long Island Sound. In: Pederson J (ed) First National Conference on Marine Bioinvasions, MIT SeaGrant College Program, Cambridge, MA, p 200-207

Brousseau DJ, Baglivo JA, Filipowicz A, Sego L, Alt C (2002) An experimental field study of site fidelity and mobility in the Asian shore crab, Hemigrapsus sanguineus. Northeast Nat 9:381-390

Brown KM, Swearingen DC (1998) Effects of seasonality, length of immersion, locality and predation on an intertidal fouling assemblage in the northern Gulf of Mexico. J Exp Mar Biol Ecol 225:107-121

Buschbaum C (2000) Direct and indirect effects of Littorina littorea (L.) on barnacles growing on mussel beds in the Wadden Sea. Hydrobiologia 440:119-128

Buschbaum C (2002) Predation on barnacles of intertidal and subtidal mussel beds in the Wadden Sea. Helgol Mar Res $56: 37-43$

Caley MJC, Carr JH, Hixon MA, Hughes TP, Jones GP, Menge BA (1996) Recruitment and the local dynamics of open marine populations. Annu Rev Ecol Syst 27:477-500

Cohen ANC, Carleton JT (1998) Accelerating invasion rate in a highly invaded estuary. Science 279:555-558

Connell JH (1970) A predator-prey system in the marine intertidal region. I. Balanus glandula and several predatory species of Thais. Ecol Monogr 40:49-78

Connell JH (1985) The consequences of variation in initial settlement vs. post-settlement mortality in rocky intertidal communities. J Exp Mar Biol Ecol 93:11-45

Fishman JR, Orth RJ (1996) Effects of predation on Zostera marina L. seed abundance. J Exp Mar Biol Ecol 198: $11-26$

Fukui Y (1988) Comparative studies on the life history of the grapsid crabs (Crustacea, Brachyura) inhabiting intertidal cobble and boulder shores. Publ Seto Mar Biol Lab 33: 121-162

Gerard VA, Cerrato RM, Larson AA (1999) Potential impacts of a western Pacific grapsid crab on intertidal communities of the northwestern Atlantic Ocean. Biol Invasions 1: 353-361

Grosholz ED, Ruiz GM, Dean CA, Shirley KA, Maron JL, Connors JP (2000) The impacts of a nonindigenous marine predator in a California bay. Ecology 81:1206-1224

Holmes SP, Walker G, van der Meer J (2005) Barnacles, limpets and periwinkles: the effects of direct and indirect interactions on cyprid settlement success. J Sea Res 53: 181-204

Jeffrey CJ (2003) Determination of abundance and distribution of an intertidal barnacle: settlement or postsettlement mortality? Mar Ecol Prog Ser 246:291-305

Jensen GC, McDonald PS, Armstrong DA (2002) East meets west: competitive interactions between green crab Carcinus maenas and native and introduced shore crab Hemigrapsus spp. Mar Ecol Prog Ser 225:251-262

Lambert WJ, Levin PS, Berman J (1992) Changes in the structure of a New England (USA) kelp bed: the effects of an introduced species? Mar Ecol Prog Ser 88:303-307

Lang WH, Ackenhusen-Jones A (1981) Seasonal species composition of barnacle larvae (Cirripedia:Thoracica) in Rhode Island waters, 1977-1978. J Plankton Res 3: 567-575

Lohrer AM, Whitlatch RB (1997) Ecological studies on the recently introduced Japanese shore crab (Hemigrapsus sanguineus) in eastern Long Island Sound. In: Balcom NC (ed) Proc 2nd Northeast Conference on Nonindigenous Aquatic Nuisance Species. Connecticut Sea Grant College, Groton, p 49-60

Lohrer AM, Whitlatch RB (2002) Relative impacts of two exotic brachyuran species on blue mussel populations in Long Island Sound. Mar Ecol Prog Ser 227:135-144

Lubchenko J, Menge B (1978) Community development and persistence in a low rocky intertidal zone. Ecol Monogr 48: $67-94$

McDermott JJ (1998a) The western Pacific brachyuran (Hemigrapsus sanguineus: Grapsidae) in its new habitat along the Atlantic coast of the United States: reproduction. J Crustac Biol 18:308-316

McDermott JJ (1998b) The western Pacific brachyuran Hemigrapsus sanguineus (Grapsidae) in its new habitat along the Atlantic coast of the United States: feeding, cheliped morphology and growth. In: Schram FR, Von Vaupel Klein JC (eds) Crustaceans and the biodiversity crisis. Brill, Leiden, p 425-444 
Miller KM, Carefoot TH (1989) The role of spatial and size refuges in the interaction between juvenile barnacles and grazing limpets. J Exp Mar Biol Ecol 134:157-174

Minchinton TE, Scheibling RE (1993) Free space availability and larval substratum selection as determinants of barnacle population structure in a developing rocky intertidal community. Mar Ecol Prog Ser 95:233-244

Moksnes PO, Heck KL Jr. (2006) Relative importance of habitat selection and predation for the distribution of blue crab megalopae and young juveniles. Mar Ecol Prog Ser 308: 165-181

Nichols FH, Thompson JK, Schemel LE (1990) Remarkable invasion of San Francisco Bay (California, USA) by the Asian clam Potamacorbula amurensis. II. Displacement of a former community. Mar Ecol Prog Ser 66:95-101

Paine RT (1966) Food web complexity and species diversity. Am Nat 100:65-75

Parks S, Epifanio CE, Grey EK (2004) Behavior of larval Hemigrapsus sanguineus (de Haan) in response to gravity and pressure. J Exp Mar Biol Ecol 307:197-206

Editorial responsibility: Roger Hughes (Contributing Editor), Bangor, UK
Rodriguez SR, Ojeda FP, Inestrosa NC (1993) Settlement of benthic marine invertebrates. Mar Ecol Prog Ser 97: 193-207

Thrush SF (1986) Community structure on the floor of a sealough. Are large epibenthic predators important? J Exp Mar Biol Ecol 104:171-184

Travis J (1993) Environmental science: invaders threaten the Black Sea. Science 262:1366-1367

Tyrell MC, Guarino PA, Harris LG (2006) Predatory impacts of two introduced species: inferences from microcosms. Northeast Nat 13:375-390

Walton WC, MacKinnon C, Rodriguez LF, Proctor C, Ruiz G (2002) Effect of an invasive crab upon a marine fishery: green crab, Carcinus maenas, predation upon a venerid clam, Katelysia scalarina, in Tasmania (Australia). J Exp Mar Biol Ecol 272:171-189

Williams AB, McDermott JJ (1990) An eastern United States record for the western Indo-Pacific crab, Hemigrapsus sanguineus (Crustacea:Decapoda:Grapsidae). Proc Biol Soc Wash 103:108-109

Submitted: July 14, 2006; Accepted: November 23, 2006 Proofs received from author(s): May 22, 2007 